PRELIMINARY COMMUNICATION

\section{Possible Role of Laxatives in Analgesic Nephropathy}

\section{J. S. WAINSCOAT, RONALD FINN}

British Medical fournal, 1974, 4, 697-698

\section{Summary}

Eight out of ten of patients with analgesic nephropathy were regular and usually heavy laxative takers compared with 12 out of 200 controls from the general population and four out of 70 patients attending a renal clinic. The finding that regular laxative taking was greatly increased in patients with analgesic nephropathy suggests that this condition may often be due to the combined abuse of both laxatives and analgesics. In a series of $\mathbf{4 0}$ patients with rheumatoid arthritis all were found to have normal renal function and no patient took laxatives regularly. This finding would explain why analgesic nephropathy is so uncommon in patients with rheumatoid arthritis despite the fact that they are regular and heavy analgesic takers.

\section{Introduction}

Analgesic nephropathy is a well-documented condition (Gault et al., 1968; Cove-Smith and Knapp, 1973) with a yearly incidence in England and Wales of at least 500 new cases (Koutsaimanis and De Wardener, 1970). Many patients, however, take large quantities of analgesics, including phenacetin, for many years and it remains unexplained why only a very small percentage develop renal damage. This paradox has even led some critics to doubt whether analgesic nephropathy is a true entity (Sorenson, 1966). One of us (J.W.) suggested that laxatives may potentiate the nephroxicity of analgesics, including

Renal Unit, Sefton General Hospital, Liverpool L15 2HE and the Department of Medicine, University of Liverpoo

J. S. WAINSCOAT, M.B., CH.B., Senior House Officer

RONALD FINN, M.D., F.R.C.P., Consultant Physician phenacetin, and that the combination of these drugs is responsible for many cases of analgesic nephropathy. We here present evidence in support of this hypothesis.

\section{Patients and Methods}

Four groups of patients were studied. Group 1 consisted of 10 consecutive cases of analgesic nephropathy seen by us (table I). The criteria for the diagnosis were: a history of regular and prolonged analgesic abuse. All patients were estimated to have consumed at least $5 \mathrm{~kg}$ of aspirin or phenacetin; absence of any other cause of renal disease; a plasma creatinine of at least $2 \mathrm{mg} / 100 \mathrm{ml}$. Group 2 consisted of 70 patients attending the renal clinic who were chosen to act as controls for group 1 as they had a similar range of renal function and age. Group 3 consisted of 200 healthy blood donors who were interviewed to investigate the relationship between laxative and analgesic consumption in the general population. Group 4 consisted of 40 patients with rheumatoid arthritis. All had taken large quantities of analgesics for at least five years.

A detailed drug history was taken from all patients and particular attention was paid to analgesics and laxatives. The patients were divided into three broad groups according to their laxative and analgesic consumption: regular takers, who took laxatives or analgesics or both more than twice a week; occasional takers, who took drugs less than twice a week but more than once a month; and "non-takers," who took drugs less than once a month.

\section{Results}

Laxative Intake.-The incidence of laxative taking in the four groups of patients is shown in table II. Eight of the 10 patients with analgesic nephropathy (group 1) were regular laxative takers in comparison to four out of $70(5.7 \%)$ renal clinic patients (group 2) and 12 out of 200 (6\%) blood donors (group 3 ). Among the 40 patients with rheumatoid arthritis (group 4) there were no regular laxative takers. Thus, the incidence of regular laxative taking in patients with analgesic nephropathy was significantly higher than in the other three groups of patients $(P<0.001)$. Similarly, there was a significantly higher incidence of laxative takers of all sorts among the patients with analgesic nephropathy compared with the other three groups $(P<0.01)$.

Rheumatoid Arthritis. - Among the $\mathbf{4 0}$ patients with rheumatoid arthritis 15 out of $40(37.5 \%)$ were occasional laxative

TABLE I-Clinical Details of 10 Patients with Analgesic Nephropathy

\begin{tabular}{|c|c|c|c|c|c|c|}
\hline $\begin{array}{l}\text { Case } \\
\text { No. }\end{array}$ & $\begin{array}{l}\text { Age and } \\
\text { Sex }\end{array}$ & $\begin{array}{c}\text { Plasma Creatinine } \\
(\mathrm{mg} / 100 \mathrm{ml})\end{array}$ & $\begin{array}{c}\text { Plasma Potassium* } \\
(\mathrm{mEq} / 1 .)\end{array}$ & Analgesic History & Laxative History $\dagger$ & Comments \\
\hline 1 & $54 M$ & $12 \cdot 8$ & $3 \cdot 4$ & Phenacetin 15 yr, Sonalgin & Senokot $9 /$ week & $\begin{array}{l}\text { Psychiatric treatment for } \\
\text { depression }\end{array}$ \\
\hline $\begin{array}{l}2 \\
3 \\
4\end{array}$ & $\begin{array}{l}60 M \\
31 M \\
28 M\end{array}$ & $\begin{array}{r}5 \cdot 0 \\
14 \cdot 0 \\
16 \cdot 0\end{array}$ & $\begin{array}{l}4 \cdot 3 \\
3 \cdot 2 \\
3 \cdot 6\end{array}$ & $\begin{array}{l}\text { Aspirin, } 30 \text { phenacetin yr } \\
\text { Aspirin } 15 \mathrm{yr} \\
\text { Codis } 5 \mathrm{yr}\end{array}$ & $\begin{array}{l}\text { Senokot } 6 / \text { week } \\
\text { Senokot } 4 / \text { week } \\
\text { Senokot 30/week }\end{array}$ & $\begin{array}{l}\text { Gross personality disorder, } \\
\text { cathartic colon }\end{array}$ \\
\hline $\begin{array}{l}5 \\
6\end{array}$ & $69 \mathrm{M}$ & $\begin{array}{l}6.9 \\
5.8\end{array}$ & $\begin{array}{l}2 \cdot 4 \\
2.8\end{array}$ & $\begin{array}{l}\text { Aspirin, Codis } 6 \text { yr } \\
\text { Aspirin, Codis } 10 \text { yr }\end{array}$ & $\begin{array}{l}\text { Various laxatives } 4 / \text { week } \\
\text { Daily liquid paraffin, } \\
\text { occasionally others }\end{array}$ & \\
\hline $\begin{array}{l}7 \\
8\end{array}$ & $\begin{array}{l}65 \mathrm{~F} . \\
20 \mathrm{~F} .\end{array}$ & $\begin{array}{l}2 \cdot 7 \\
2 \cdot 3\end{array}$ & $\begin{array}{l}2 \cdot 6 \\
3 \cdot 5\end{array}$ & $\begin{array}{l}\text { Compound codeine } 15 \mathrm{yr} \\
\text { Aspirin } 6 \mathrm{yr}\end{array}$ & $\begin{array}{l}\text { Senokot } 4 / \text { week } \\
\text { Liquid paraffin until age } 10 \text {, } \\
\text { then Senokot } 3 / \text { week }\end{array}$ & $\begin{array}{l}\text { Gross neurotic personality } \\
\text { Depression }\end{array}$ \\
\hline 9 & $62 \mathrm{~F}$. & $9 \cdot 2$ & $4 \cdot 5$ & Codis $10 \mathrm{yr}$ & $\begin{array}{l}\text { Occasional assorted laxatives } \\
\text { 2/month }\end{array}$ & \\
\hline 10 & $41 \mathrm{M}$. & $7 \cdot 7$ & 3.5 & Aspirin, Phensic 8 yr & $\mathrm{Nil}^{2 / \text { monim }}$ & $\begin{array}{l}\text { Severe hypertension resistant } \\
\text { to treatment. }\end{array}$ \\
\hline
\end{tabular}


TABle II-Laxative Taking in Patients with Analgesic Nephropathy (Group 1) and Patients with Rheumatoid Arthritis (Group 4) compared with Two Control Populations

\begin{tabular}{c|c|c|c}
\hline Group & $\begin{array}{c}\text { No. of } \\
\text { Patients }\end{array}$ & $\begin{array}{c}\text { Regular Laxative } \\
\text { Takers }\end{array}$ & $\begin{array}{c}\text { All Laxative Takers } \\
(>1 / \text { month) }\end{array}$ \\
\cline { 2 - 3 } & 10 & No. (\%) & No. (\%) \\
\hline 1 & 70 & $8(80)$ & $9(90)$ \\
3 & 200 & $12(5 \cdot 7)$ & $16(22 \cdot 9)$ \\
4 & 40 & $42(21)$ & $15(37 \cdot 5)$ \\
\hline
\end{tabular}

takers. The mean plasma creatinine for the laxative takers (see fig.) was $0.97 \mathrm{mg} / 100 \mathrm{ml}$ compared with $0.74 \mathrm{mg} / 100 \mathrm{ml}$ for the "non-laxative" group, a statistically significant difference $(t=2.20$; 38 D.F.; $P<0.05)$. The mean ages of the two series were 58 years and 54 years respectively.

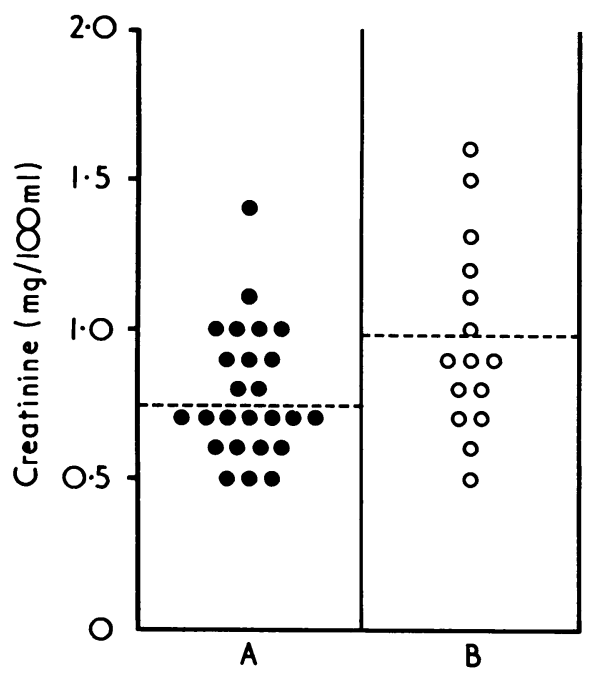

Plasma creatinine in patients with rheumatoid arthritis in relation to their laxative habits. $\mathbf{A}=$ Non-takers $(<1 /$ month). $\mathbf{B}=$ Laxative takers $(>1$ l month). Horizontal dotted lines represent means.

\section{Discussion}

Spuhler and Zollinger in 1953 first drew attention to the association between a high intake of analgesics and chronic interstitial nephritis. Since then numerous reports have accumulated and it is now generally accepted that analgesic nephropathy is a true disease entity (Gault et al., 1968; Levin, 1969; British Medical fournal, 1970). On the other hand, it is a matter of common clinical experience that the vast majority of patients who take large quantities of analgesics for long periods do not develop renal damage (Macklon et al., 1974). Our results provide an explanation for this paradox and give support to the hypothesis that analgesic nephropathy is more likely to occur in patients who abuse both analgesics and laxatives.

Regular laxative taking is relatively uncommon. In our control group of healthy blood donors (average age 41) the incidence was $6 \%$, a finding that agrees with those of other studies in the general-population (Connell et al., 1965). In marked contrast, $80 \%$ of our patients with analgesic nephropathy (average age 46) were heavy laxative takers. These findings suggest a relationship between analgesic and laxative abuse and provide strong support for the hypothesis that analgesic nephropathy is often due to the combined abuse of these two types of drugs. As the combined abuse of laxatives and analgesics is rare this could explain why most patients who take large quantities of analgesics, including phenacetin do not develop renal damage.

Though renal failure does occur in rheumatoid arthritis it is uncommon and several authors have reported series of patients with rheumatoid arthritis who had taken large amounts of analgesics for many years without developing renal damage (New Zealand Rheumatism Association, 1974; Macklon et al., 1974). We have studied a random group of 40 patients with long-standing rheumatoid arthritis who had all taken massive quantities of analgesics, including phenacetin in many cases, without developing renal damage. Detailed drug historys were taken and not a single regular laxative taker was found. There were $15(37.5 \%)$ occasional laxative takers, and the mean plasma creatinine of this group was slightly higher than that of the "non-takers" with rheumatoid arthritis $(P<0.05)$. The mean age of the occasional laxative takers was four years greater than that of the "non-takers". Though plasma creatinine does rise slightly with age the difference over a four-year period is insignificant, and these results therefore suggest that there may be a potentiating effect between the two groups of drugs.

No cases of analgesic nephropathy were discovered among this random group of patients with rheumatoid arthritis. Clearly, regular laxative abuse is uncommon in patients with rheumatoid arthritis, which would explain the finding of several workers that analgesic nephropathy is unusual in this condition despite the fact that these patients have often taken large quantities of analgesics, including phenacetin.

Requests for reprints should be sent to Dr. R. Finn.

\section{References}

British Medical fournal, (1970). 4, 125.

Connell, A. M., et al. (1965). British Medical fournal, 2, 1095.

Cove-Smith, J. R., and Knapp, M. S. (1973). Lancet, 2, 70.

Gault, M. H., et al. (1968). Annals of Internal Medicine, 68, 906

Koutsaimanis, K. G., and de Wardener, H. D. (1970). British Medical fournal, 4, 131 .

Levin, N. W. (1969). Fournal of Chronic Diseases, 21, 527.

Macklon, A. F., et al. (1974). British Medical fournal, 1, 597

New Zealand Rheumatism Association Study. (1974). British Medical fournal, 1, 593 .

Sorenson, A. W. S. (1966). Nephron, 3, 366.

Spuhler, O., and Zollinger, H. U. (1953). Zeitzchrift für klinische Medizin, 151,1 . 